\title{
Offering rainfall insurance to informal insurance groups: evidence from a field experiment in Ethiopia*
}

\author{
Stefan Dercon ${ }^{1}$, Ruth Vargas Hill ${ }^{2}$, Ingo Outes-Leon ${ }^{1}$, Daniel Clarke ${ }^{1}$, and Alemayehu \\ Seyoum Taffesse ${ }^{2}$ \\ ${ }^{1}$ University of Oxford \\ ${ }^{2}$ International Food Policy Research Institute
}

October 2012

\begin{abstract}
We report the results from a first attempt to market weather insurance products to informal risk-sharing groups. In collaboration with a leading insurance company in Ethiopia, we marketed index-based rainfall insurance products to members of pre-existing risk-sharing groups. Leaders and members of risk sharing groups were trained on risk management and the possible benefits of insurance. Among those trained we randomized training, with some sessions focusing on the benefits of sharing insurance. We found that members of groups whose leaders had received training that emphasized risk-sharing had considerably higher uptake. Our results suggest benefits from marketing index-based insurance to insurance groups, at least in terms of uptake.
\end{abstract}

Keywords: insurance; risk-sharing; Ethiopia

\section{Introduction}

Rainfall risk remains a key problem for Ethiopian farmers. In a recent survey conducted in 2009, $44 \%$ of farmers reported serious losses in wealth and consumption due to drought in last 4 years, and $22 \%$ report losses due to too much rain and floods. Rainfall risk also seems to affect the uptake of modern inputs in Ethiopia. Dercon and Christiaensen (2011) report a strong link between willingness to take up fertilizer and weather risk in Ethiopia. This would suggest that these farmers are likely to be interested in insurance.

Crop insurance, based on offering indemnity against crop losses, is fraught with problems, linked to incentives, costly verification and high transactions costs. More recently, index-based products are increasingly promoted as an alternative, as they offer payouts based on easily observable data, without verification or incentive problems, reducing transactions costs (Skees et al., 1999; Barnett

\footnotetext{
${ }^{*}$ We gratefully acknowledge funding from the International Growth Centre (http://www.theigc.org/), funded by the Department for International Development under the research grant "Drought and informal insurance groups: A randomized intervention of index-based rainfall insurance in rural Ethiopia" led by the Department of International Development, University of Oxford; and from the grant competition organised by Agence Franaise de Développment, The Bill and Melinda Gates Foundation and the World Bank during the Marketplace on Innovative Finance for Development on the 4th and 5th of March 2010 in Paris. We thank participants of the FERDI workshop on groupbased index insurance for useful comments.
} 
and Mahul, 2007). In this paper, we will study rainfall insurance products that offer a payout when rainfall falls below a particular level, measured at a local rainfall station.

In practice, uptake of index insurance products appears to be low in agriculture in poor settings. For example, Giné et al. (2008) report about 5\% uptake for a region in Andhra Pradesh in India; Cole et al. (2009), report uptakes of about 5-10\% in Andhra Pradesh and Gujarat. In Malawi, Giné and Yang (2009) report that fewer people take up a loan with insurance than a loan without insurance (20 vs 33\%). Uptake patterns are also puzzling, with richer people buying more, and the more risk averse buying less. Explanations offered include the role of trust, credit constraints or poor understanding (Cole et al., 2009).

Trust and poor understanding of insurance are general explanations often offered to explain why people are not taking up insurance in poor settings (e.g. Cai et al. (2009) in China or Dercon et al. (2011) in Kenya). They may also hold true for index-insurance products. The same trust in the insurance company is required, and even though it is easy to understand that the payout is linked to levels of rainfall at a particular location, the presence of basis risk, which is the difference between the losses actually incurred and the losses insured, makes this decision much more complicated. Clarke (2011b) highlights that index products are not standard insurance products and that basis risk means that compared to the original risk distribution faced, there will be states of the world in which the net loss is actually higher (as an actual loss is faced, but the trigger shows that there is no rainfall failure) and states of the world in which gains are made (as there is no loss incurred, but the trigger results in a payout). ${ }^{1}$ Basis risk also makes the index insurance product relatively more costly from the point of view of the farmer than a product that is priced relative to actual losses, even if both are actuarially priced relative to the risk that is insured.

One possible way of overcoming some of these problems is to offer products as group contracts. Groups could internalize many problems of understanding the product, improving the quality of decision making. They could also be better placed to enforce contracts. Per policy transaction costs would also likely be lower when insurance is purchased "in bulk" through a group. Importantly, they could also be a means to manage basis risk, to the extent that not all basis risk is perfectly correlated among its members. If group based contracts could also imply commitments to share risk within the group, then better value can be offered to farmers.

In this paper, we explore whether groups can manage basis risk thereby increasing demand for index insurance. We set out a conceptual framework to show that risk-sharing and index insurance are complementary, and we report the results from a first attempt to market weather insurance products to informal risk-sharing groups.

We provide a theoretical proof that shows that, under quite general conditions, risk-sharing and index insurance are complementary with increased access to one driving up demand for the other. We also show that this is quite different to the relationship between risk-sharing and indemnity insurance, where no such complementary relationship exists.

To explore the benefits of offering insurance to groups, we collaborated with an Ethiopian insurance company to offer insurance to farmers in three districts (Meskan, Silte and Animelo), about $150 \mathrm{~km}$ west of Addis Ababa in 2010. Legal and reputational concerns led the insurance company to insist on contracts with individual farmers. However, the entire marketing was done towards members of an informal insurance group, the iddir, which are funeral societies. These groups are widespread in Ethiopia, with virtually every household a member. Against the payment of a premium, it offers funeral insurance, in the form of support in cash and kind in case someone linked to the member dies. In all communities, a large number of these groups exist, with several

\footnotetext{
${ }^{1}$ One implication is that a highly risk-averse farmer faced with basis risk may be less likely to buy this product than a farmer with low risk-aversion. In related work, Clarke and Kalani (2011) find that Ethiopian farmers make considerable errors in buying such index insurance products, perhaps due to the complexity of the decision problem.
} 
dozens of members in each group. They are considered well governed and democratic institutions, with no government or NGO involvement in their functioning (Dercon et al., 2006). They appear very suitable groups to roll out insurance, as they tend to understand insurance and its functioning, and are well respected by their members and in their communities.

As part of a marketing campaign we carried out training sessions for iddir leaders and members. While all training sessions had a similar focus, introducing concepts of insurance and explaining in detail the insurance policies, we varied the content of training received by the iddir leadership. Whilst one training focused on the insurance benefits for individual farmers, other training sessions focused on the insurance benefits when risk-sharing activities are considered among group members. Members of the iddir leadership were randomly assigned to training of one of these two types.

This intervention design allows us to explore the extent to which emphasis on sharing risk did indeed generate higher demand for insurance. Because all other aspects of the marketing were held constant-the transactional and communication roles that iddir leaders played was identical across both training types-the design allows us to focus on the perceived benefits that result from emphasizing sharing policies or payouts within a group, rather than marketing advantages that groups may have as a result of encouraging trust in the insurance product or reducing transaction costs.

We test whether the content of the training sessions matter for insurance uptake. We find that iddirs in which leaders were trained in the benefits of sharing insurance had substantially higher take-up rates than iddirs in which leaders were trained in the individual benefits of insurance. Demand was some nine percentage points higher among iddirs in which leaders were trained in sharing insurance. The additional demand generated originated from both iddir leaders as well as trained regular members. We find these estimates to be robust to controlling for community fixed effects, as well as a broad set of farmer characteristics.

Our analysis also shows that these effects are not due to (coincidental) pre-intervention differences across randomized iddirs, nor due to differences in how effective training was in increasing understanding. Rather, training the iddir leadership in sharing policies and payouts encouraged leaders to involve more people in the training exercises and resulted in higher levels of risk sharing among selected members to be observed.

The results of our experiment show that the type of training provided to leaders of indigenous groups, has important implications for demand for insurance. Increased demand could have resulted because the training that emphasized group risk sharing provided one more persuasive argument in favor of index insurance. However, our analysis is consistent with the hypothesis that group members were encouraged to share some aspect of uninsured risk, thereby allowing for increased demand for the indexed product.

New insurance products are not delivered in a vacuum, as poor communities have various mechanisms to cope with risk. Existing risk sharing networks could provide a cost-effective means of spreading innovative risk management mechanisms such as insurance. The paper provides the first evidence that the notional benefits of marketing campaigns that encourage groups to combine these products with increased risk sharing amongst members might be large, resulting in substantially larger take-up rates. As insurance is not an easy concept, as it requires considerable trust, and as it can be perceived to be costly, finding delivery mechanisms that provide an appropriate link with the target group are crucial to achieve higher take-up.

The findings are also consistent with the hypothesis that strengthening mechanisms to manage basis risk makes index insurance attractive to small-holder farmers. The presence of basis risk in index-based insurance means that even actuarially fairly priced insurance products may not be attractive to risk-averse farmers. Understanding mechanisms to manage this basis risk deserve further attention. 


\section{Conceptual Framework}

Providing insurance through groups could carry a number of possible advantages. Selling through groups reduces the costs of retailing insurance: training can be organized with group leaders; and group leaders can subsequently train members, assemble a list of demands, collect premium payments, and distribute insurance certificates and claims to members. In practice any type of group can be used to retail insurance in this way. As long as contracts are still made in which the coverage of individual members is individually recorded, the purpose of the group is to act as a retailer and nothing else.

Training group leaders in the insurance product also has additional advantages: they are often more literate and numerate than other members of the group so may be able to understand the products quickly in a training session and then communicate the key concepts effectively to other members. And by vouching for the insurance products they can increase trust in the insurance products among other members of the group.

We focus our research question on whether groups can provide an additional benefit in the case of index insurance. All insurance was retailed through groups in our research and all training was initially provided to group leaders. However the message of the training sessions was varied, such that in some sessions selected groups members were encouraged to increase the amount of agricultural risk they shared among each other to complement the partial cover from the index insurance product. This message may have increased demand purely by virtue of being one more persuasive argument in favor of index insurance; however in this section we discuss why the nature of this altered message may have a direct effect on increasing take-up. Specifically we ask whether increased risk-sharing among group members can alter their demand for index insurance products, and correspondingly whether a decision to purchase index insurance can alter their demand for risk-sharing.

To capture the essence of the interaction between risk-sharing and index insurance purchase consider the following model. There are two agents, 1 and 2. Preferences for agent $i$ are represented by a von Neumann-Morgenstern utility function $u_{i}$, defined over own consumption $c_{i}$. Agents are strictly non-satiated and risk-averse, that is $u_{i}^{\prime}>0$ and $u_{i}^{\prime \prime}<0$ everywhere for both agents $i$. Moreover, we will assume that agents preferences satisfy prudence $\left(u_{i}^{\prime \prime \prime}>0\right)$ and temperance $\left(u_{i}^{\prime \prime \prime \prime}<\right.$ 0). Whilst originally coined by Kimball (1990) and Kimball (1992) respectively in reference to their roles in characterising precautionary savings decisions, they have wider relevance in characterizing behavior when there is more than one source of uncertainty as will be the case in our model, and have been recently defined in terms of preferences between sets of lottery pairs by Eeckhoudt and Schlesinger (2006). ${ }^{2}$

Each agent $i$ has initial wealth $w_{i}$ and is subject to uncertain binary loss $x_{i}$ which can take values in $\{0, \bar{x}\}$. We consider two types of insurance product. The first kind of insurance product is actuarially fair individual indemnity insurance for agent $i$, which pays agent $i$ a net amount $\alpha_{i}\left(x_{i}-\mu_{x_{i}}\right)$ where $\alpha_{i} \geq 0$ denotes the proportional rate of insurance purchased and $\mu_{x_{i}}:=\mathbb{E}\left[x_{i}\right]$. The second kind of insurance product we consider is actuarially fair index insurance, which pays agent $i$ a net amount $\alpha_{i}\left(y-\mu_{y}\right)$ where $\alpha_{i} \geq 0$ again denotes the proportional rate of insurance purchased and $y$ is a random indexed claim payment, taking values in the interval $[0, \bar{y}]$. A state of

\footnotetext{
${ }^{2}$ Eeckhoudt and Schlesinger (2006) define compound lottery $B_{3}(k, \tilde{\varepsilon})$ as giving $-k$ with probability $\frac{1}{2}$ and $\tilde{\varepsilon}$ with probability $\frac{1}{2}, A_{3}(k, \tilde{\varepsilon})$ as giving 0 with probability $\frac{1}{2}$ and $\tilde{\varepsilon}-k$ with probability $\frac{1}{2}, B_{4}\left(\tilde{\varepsilon}_{1}, \tilde{\varepsilon}_{2}\right)$ as giving $\tilde{\varepsilon}_{1}$ with probability $\frac{1}{2}$ and $\tilde{\varepsilon}_{2}$ with probability $\frac{1}{2}$, and $A_{4}\left(\tilde{\varepsilon}_{1}, \tilde{\varepsilon}_{2}\right)$ as giving 0 with probability $\frac{1}{2}$ and $\tilde{\varepsilon}_{1}+\tilde{\varepsilon}_{2}$ with probability $\frac{1}{2}$. They then show that prudence is equivalent to preferring $B_{3}(k, \tilde{\varepsilon})$ to $A_{3}(k, \tilde{\varepsilon})$ for all initial wealth levels, all $k>0$, and all zero-mean $\tilde{\varepsilon}$, and that temperance is equivalent to preferring $B_{4}\left(\tilde{\varepsilon}_{1}, \tilde{\varepsilon}_{2}\right)$ to $A_{4}\left(\tilde{\varepsilon}_{1}, \tilde{\varepsilon}_{2}\right)$ for all initial wealth levels and all zero-mean statistically independent $\tilde{\varepsilon}_{1}, \tilde{\varepsilon}_{2}$.
} 
the world is therefore a triplet $s=\left(x_{1}, x_{2}, y\right) \in S:=\{0, \bar{x}\}^{2} \times[0, \bar{y}]$. Denoting the joint cumulative density function as $F\left(x_{1}, x_{2}, y\right)$ we will make the following assumption:

Assumption 1. The joint distribution is symmetric in $x_{1}$ and $x_{2}$, i.e. $F\left(x_{1}, x_{2}, y\right)=F\left(x_{2}, x_{1}, y\right)$ for all $\left(x_{1}, x_{2}, y\right) \in S$.

Moreover, we will assume that the index insurance has been designed to capture aggregate, not idiosyncratic shocks. Specifically, we assume that the net income from index insurance in states with idiosyncratic shocks is on average no larger than the premium $\mu_{y}$, which will ensure that index insurance purchase makes agents more, not less, vulnerable to idiosyncratic shocks. ${ }^{3}$

Assumption 2. $\mathbb{E}\left[y \mid\left(x_{1}, x_{2}\right) \in\{(0, \bar{x}),(\bar{x}, 0)\}\right] \leq \mathbb{E}[y]$.

Agents may choose to commit to symmetric risk sharing with each other, with agent $i$ making a transfer of $\theta \bar{x}$ to agent $j \neq i$ if agent $j$ incurs a loss of $\bar{x}$ but agent $i$ does not incur a loss. We assume $0 \leq \theta \leq \frac{1}{2}$ and so $\theta=0$ corresponds to no risk sharing and $\theta=\frac{1}{2}$ corresponds to full risk sharing. The random net wealth of agent $i$ therefore depends both on agent $i$ 's insurance purchase decision $\alpha_{i}$ and the joint risk-sharing decision $\theta$, resulting in net realised wealth for agent $i$ of

$$
\begin{gathered}
\text { Indemnity insurance offered: } w_{i}-x_{i}+\theta\left(x_{i}-x_{j}\right)+\alpha_{i}\left(x_{i}-\mu_{x_{i}}\right) \\
\text { Index insurance offered: } w_{i}-x_{i}+\theta\left(x_{i}-x_{j}\right)+\alpha_{i}\left(y-\mu_{y}\right)
\end{gathered}
$$

when offered the indemnity and index insurance products respectively.

It is well understood that individual indemnity insurance can reduce informal within-community risk-sharing, and that informal risk-sharing can crowd out demand for individual indemnity insurance (e.g. Arnott and Stiglitz (1991) and Attanasio and Rios-Rull (2000)). For example, if one considers agent $i$ 's demand for individual indemnity insurance we have the following result.

Theorem 1. Within-group risk sharing and indemnity insurance are substitutes in the sense that an increase in one will reduce optimal demand for the other.

Proof. Using equation (1) we may write agent $i$ 's expected utility in the indemnity insurance problem as

$$
U_{i}\left(\alpha_{i}, \theta\right)=\int_{S} u\left(w_{i}-x_{i}+\theta\left(x_{i}-x_{j}\right)+\alpha_{i}\left(x_{i}-\mu_{x_{i}}\right)\right) d F(s) .
$$

It is sufficient to show that this exhibits weakly decreasing differences in $\left(\alpha_{i}, \theta\right)$, that is $\frac{\partial^{2} U\left(\alpha_{i}, \theta\right)}{\partial \alpha_{i} \partial \theta} \leq 0$. We have

$$
\frac{\partial^{2} U\left(\alpha_{i}, \theta\right)}{\partial \alpha_{i} \partial \theta}=\int_{S}\left(x_{i}-x_{j}\right)\left(x_{i}-\mu_{x_{i}}\right) u^{\prime \prime}\left(w_{i}-x_{i}+\theta\left(x_{i}-x_{j}\right)+\alpha_{i}\left(x_{i}-\mu_{x_{i}}\right)\right) d F(s) .
$$

Now

$$
\left(x_{i}-x_{j}\right)\left(x_{i}-\mu_{x_{i}}\right)= \begin{cases}0 & \text { if }\left(x_{i}, x_{j}\right)=(0,0) \text { or }(\bar{x}, \bar{x}) \\ \bar{x} \mu_{x_{i}} & \text { if }\left(x_{i}, x_{j}\right)=(0, \bar{x}) \\ \bar{x}\left(\bar{x}-\mu_{x_{i}}\right) & \text { if }\left(x_{i}, x_{j}\right)=(\bar{x}, 0)\end{cases}
$$

and since $\bar{x} \geq \mu_{x_{i}}$ and $u^{\prime \prime}<0$ everywhere it must be that $\frac{\partial^{2} U\left(\alpha_{i}, \theta\right)}{\partial \alpha_{i} \partial \theta} \leq 0$.

\footnotetext{
${ }^{3}$ This assumption is more general than that of Mobarak and Rosenzweig (2012), in which $\mathbb{E}\left[y \mid\left(x_{1}, x_{2}\right) \in\right.$ $\{(0, \bar{x}),(\bar{x}, 0)\}]=\mathbb{E}\left[y \mid\left(x_{1}, x_{2}\right)=(0,0)\right]$ is also assumed.
} 
However, as we now show in our main theoretical result, this intuition does not follow through to index insurance. Instead, the opposite holds: Assumption 1 ensures that the claim payment from index insurance is more strongly correlated with the average loss than with either agent's individual loss, making the product more valuable when it is used in conjunction with risk-sharing than when without. Moreover, risk-sharing only offers protection against idiosyncratic shocks, and this is more valuable when index insurance is purchased as payment of the index insurance premium increases vulnerability to idiosyncratic shocks.

Theorem 2. Within-group risk sharing and index insurance are complements in the sense that an increase in one will reduce optimal demand for the other.

Proof. Using equation (2) we may write agent $i$ 's expected utility in the index insurance problem as

$$
V_{i}\left(\alpha_{i}, \theta\right)=\int_{S} u\left(w_{i}-x_{i}+\theta\left(x_{i}-x_{j}\right)+\alpha_{i}\left(y-\mu_{y}\right)\right) d F(s)
$$

It is sufficient to show that this exhibits weakly increasing differences in $\left(\alpha_{i}, \theta\right)$, that is $\frac{\partial^{2} V\left(\alpha_{i}, \theta\right)}{\partial \alpha_{i} \partial \theta} \geq 0$. We have

$$
\frac{\partial^{2} V\left(\alpha_{i}, \theta\right)}{\partial \alpha_{i} \partial \theta}=\int_{S}\left(x_{i}-x_{j}\right)\left(y-\mu_{y}\right) u^{\prime \prime}\left(w_{i}-x_{i}+\theta\left(x_{i}-x_{j}\right)+\alpha_{i}\left(y-\mu_{y}\right)\right) d F(s) .
$$

Now

$$
\left(x_{i}-x_{j}\right)\left(y-\mu_{y}\right)= \begin{cases}0 & \text { if }\left(x_{i}, x_{j}\right)=(0,0) \text { or }(\bar{x}, \bar{x}) \\ -\bar{x}\left(y-\mu_{y}\right) & \text { if }\left(x_{i}, x_{j}\right)=(0, \bar{x}) \\ \bar{x}\left(y-\mu_{y}\right) & \text { if }\left(x_{i}, x_{j}\right)=(\bar{x}, 0)\end{cases}
$$

and so applying Assumption 1 and denoting the cumulative density function of $y$ conditional on $\left(x_{1}, x_{2}\right) \in\{(0, \bar{x}),(\bar{x}, 0)\}$ as $G(y)$ we may write equation (3) as

$$
\begin{gathered}
\frac{\partial^{2} V\left(\alpha_{i}, \theta\right)}{\partial \alpha_{i} \partial \theta}=\int_{0}^{\bar{y}} \frac{\bar{x}\left(y-\mu_{y}\right)}{2}\left[u^{\prime \prime}\left(w_{i}-(1-\theta) \bar{x}+\alpha_{i}\left(y-\mu_{y}\right)\right)\right. \\
\left.-u^{\prime \prime}\left(w_{i}-\theta \bar{x}+\alpha_{i}\left(y-\mu_{y}\right)\right)\right] d G(y)
\end{gathered}
$$

We have that $y-\mu_{y}$ is nonpositive for all $y \leq \mu_{y}$ and nonnegative for all $y \geq \mu_{y}$, and has nonpositive expectation by Assumption 2, and so we are done if we can show that the term in square brackets in equation (4) is negative and weakly increasing in $y$. However, this follows directly from $u^{\prime \prime \prime}>0$ and $u^{\prime \prime \prime \prime}<0$ as we will now show.

The term in equation (4) in square brackets may be written as $u^{\prime \prime}\left(c_{A}(y)\right)-u^{\prime \prime}\left(c_{B}(y)\right)$, where $c_{A}(y):=w_{i}-(1-\theta) \bar{x}+\alpha_{i}\left(y-\mu_{y}\right)$ and $c_{B}(y):=w_{i}-\theta \bar{x}+\alpha_{i}\left(y-\mu_{y}\right)$. Now $c_{A}(y)-c_{B}(y)=$ $-(1-2 \theta) \bar{x} \leq 0$ from our assumption that $0 \leq \theta \leq \frac{1}{2}$, which restricts an increase in risk sharing to be an increase in $\theta$. Combining $c_{A}(y) \leq c_{B}(y)$ and $u^{\prime \prime \prime}>0$ we have $u^{\prime \prime}\left(c_{A}(y)\right)-u^{\prime \prime}\left(c_{B}(y)\right) \leq 0$ and combining $u^{\prime \prime \prime \prime}<0$ we have $u^{\prime \prime \prime}\left(c_{A}(y)\right)-u^{\prime \prime \prime}\left(c_{B}(y)\right) \geq 0$.

Although motivated by index insurance Theorem 2 holds for many insurance products that are not pure index insurance products. Indeed, the only restrictions we have placed on the insurance product are Assumptions 1 and 2, which would also hold for any kind of symmetric indemnity insurance targeted at aggregate shocks, such as multilateral indemnity insurance with a group 
deductible. Such products are, for example, purchased in Mexico by Fondos, semiformal selfinsurance funds for farmers, in which group indemnity insurance from a formal sector insurer protects the group against large aggregate shocks and group reserves finance idiosyncratic shocks within the group (Ibarra, 2004).

That this result holds for multilateral indemnity insurance contracts, or mixed index/multilateral indemnity insurance contracts is not surprising; Clarke (2011a) applies contracting theory to the problem of optimal collusion-proof multilateral insurance contracts between an insurer and multiple agents who have informational advantages over the insurer, and finds that the optimal contract involves the group of agents sharing idiosyncratic shocks and the insurer offering protection against aggregate shocks. Moreover, such group insurance contracts can be used to crowd in risk sharing even in the presence of limited commitment. Nonetheless, Theorem 2 clarifies the generality of Clarke's (2011) result beyond pure indemnity insurance contracts, showing that index insurance can also crowd in informal risk sharing.

Our model assumes that the degree of risk-sharing $\theta$ is a choice, but in practice this may be constrained, for example due to limited commitment on the part of the agents (Coate and Ravallion, 1993). However, Theorems 1 and 2 still provide valuable intuition in such cases by indicating the optimal choices by agents in the absence of limited commitment.

For complementarities between index insurance and group risk sharing to be achieved in practice a group must develop clear rules whereby members are paid conditional on an assessment of actual losses by other members within the group. Only when such rules can be institutionalized, indexinsurance can be bought by the group to insure (or reinsure) the group as a whole.

The extent to which shocks are idiosyncratic or systematic will determine how large an effect such mutualization will have on demand. For example, if shocks are very highly correlated or if there is already full risk sharing within groups one would expect little or no impact from offering insurance to groups instead of individuals. However, if current risk sharing is weak and there is plenty of idiosyncratic risk, as seems to be the case for communities in our experiment, the potential benefits are larger.

In our study, we market group-insurance to pre-existing iddirs or traditional funeral societies, which are the most widespread and inclusive of all informal institutions across rural Ethiopia. Historically, iddirs have been informal arrangements aimed at providing support to households at time of a funeral. Members' contributions were mostly made at the time of a funeral, however over the past two decades iddirs have started to formalize and provide more services to members (Dercon, de Weerdt, Bold and Pankhurst 2005; Bold and Dercon 2009). In general the iddir activities are now formalized in that they collect regular premiums, and payout in cash and in kind at the time of a funeral in a member's family. This is the main source of support that iddirs provide, and for most iddirs is the only form of grant (i.e. non-loan) payments made. In addition to providing cash and grain at the time of a funeral, some iddirs have started to diversify into other activities such as livestock insurance for livestock-owning members, fire insurance and health insurance through a system of emergency loans. Typical size in most of rural Ethiopia is about 50-100 members per iddir. With very few exceptions all households are members of one iddir. Iddirs do not have links with either government or NGOs.

All iddir leaders in our study participated in a training on weather index insurance products that were being sold. We randomly allocated leaders of some iddirs to attend a training session in which the idea of sharing idiosyncratic agricultural risk within a group was suggested as a complement to index insurance purchase. If this was a new idea to these group leaders or such risk sharing had been considered in the past but dismissed due to concerns about an iddir going bankrupt in the aftermath of a large covariate shock, if they were able to implement this idea among the entire group or a sub-groups of members, and if idiosyncratic risk was sufficiently high, then we would 
expect take-up in these groups to be higher as a result.

In the following sections we describe the treatment in more detail, show the degree to which a training that increased the salience of sharing idiosyncratic risk increased demand, and explore how and why this increased demand resulted. The mechanism that we have outlined here provides one way by which the training we describe could result in increased demand, if the training increased interest in the insurance product for other reasons, perhaps because it presented one more persuasive argument to leaders in favor of index insurance, the same relationship between training and demand would be observed. Where possible we explicitly test for this.

\section{Experimental Design}

\subsection{Sample selection}

Seventeen rural wards (kebeles) were selected in the Meskan, Silte and Anilemo districts (woredas). Each kebele contains 2-3 villages, and an iddir listing revealed 117 iddirs with a membership of a 100 members or more. The iddirs in these kebeles are quite old, established, on average, over thirty years ago. The oldest iddir was established in 1950, and the youngest in 2008. The mean number of member households is 175 . The majority of iddirs require regular payments on a monthly or bi-monthly basis with the yearly contribution amounting to 33 Birr on average (about $\$ 2$ using the current exchange rate of 17 Birr to $\$ 1$ ). Households receive about $\$ 60$ on the death of a member. Focus groups revealed that households are usually members of two to three iddirs and that these iddirs provide a number of other services too, such as payment in the event of livestock death and household fire, and loans for health care costs.

\subsection{Weather-index insurance products}

Nyala Insurance Share Company (NISCO) offered weather-index insurance policies in the seventeen selected kebeles. The policies offered followed a "building block" approach to product design: eight deficit rainfall products were designed, two for each of the key rainy months of the main cropping season in the area. The policies took the form of monthly contracts whereby a fixed payout would be due if the cumulative monthly millimeter precipitation recorded in the nearest National Meteorological Agency (NMA) station fell short of a particular target. For each month there were two policies with two different targets: a moderate loss target (resulting in a policy that paid out on average once in every five years) and a severe loss target (resulting in a policy that paid out on average once in every ten years). The targets were selected using historic data from the local rainfall stations and knowledge of the agronomic requirements of commonly used crops in the study areas. For more information on the policy design see Hill and Robles (2011). Both types of policy paid out 500 Birr if the rainfall fell below the cutoff and nothing otherwise. The moderate loss policy cost 100 Birr and the severe loss policy cost 50 Birr. Both policies were priced at their expected value (using historical data to assess the probability of payout). The multiple on the policy was thus 1, with project funds being used by Nyala to cover additional costs. This was done in order to encourage demand for insurance in the first year of its rollout in this area, but it is worth noting that the cost of a policy was still considerable when compared to the on average 33 Birr yearly contribution to the iddir.

NISCO uses groups in the marketing and contracting of all of its weather-index insurance contracts (Meherette, 2009). NISCO contacts the group leaders, provides them with information about the product, asks them to tell other farmers in the group about the product and to collect information on demand among group members. Interested group members fill in a demand schedule 
in which they enter their name, the size of the land they would like to insure, the crops they grow and the policies they would like to buy. Group members sign to indicate that they are happy to ask the group leaders to act on their behalf with NISCO. The group leaders present the filled demand schedule to NISCO along with collected premiums and ask NISCO to issue the policy. NISCO issues the policy for the total insurance purchased by the group, appending the demand schedule to indicate who payments are to go to. This policy is signed by the group leaders. Certificates are issued to all members who purchased insurance. These certificates reference the collective policy number. If payouts are made NISCO issues the payment to the group leaders who are to make the disbursements to members as per the demand schedule.

NISCO normally uses this procedure to contract through farmers cooperative unions. In this pilot they agreed to contract through large iddirs (iddirs of 100 members or more) and follow the same procedure. They also agreed to the provision of basic training to iddir leaders on the policies.

\subsection{Insurance training}

In the areas of study, we identified 117 iddirs with more than 100 members to take part in the insurance training, with an average of 7 such iddirs per kebele. As part of the marketing campaign, training sessions for iddir leaders and leader-nominated members were implemented in all kebeles. Each training session lasted about 4-5 hours with a 1-2 hour lunch break in the middle.

The training sessions discussed general issues of risk and insurance, explained in detail the workings of the NISCO insurance policies, and trained farmers in how to choose the most suitable policy for them. We randomized the content of the training session across iddirs in the following way. In each kebele, we randomly allocated iddirs to two types of training exercises:

- Training A: Framed insurance as an individual decision, focused on the individual benefits of insurance, and illustrated how an individual farmer could choose the right policies for himself.

- Training B: Framed insurance as something that could benefit the community, focused on the benefits of sharing policies or payouts among members, illustrated how a group of farmers could choose the right combination of policies for themselves, and discussed how iddirs could play a role by enabling sharing of payouts within the group.

The length of each training session was kept similar across all types. Training A and B only differed in the framing and the discussion of how to make decisions in the last half hour of the training.

Randomization took place using a full list of iddirs larger than 100 members. Randomization was done using a single random draw. There was no stratification by kebele. In a number of kebeles the iddirs have developed a federated structure whereby a large iddir has several smaller "sub-iddirs" underneath it. By restricting the list of iddirs to include only iddirs of 100 members or more we were, in most cases, excluding the sub-iddirs and allocating the large iddirs to one training type or another.

All iddir leaders of the large iddir (typically a committee of 3-5), and leaders of any of the sub-iddirs within it were eligible to attend the training session. After the leaders had received their training, leaders nominated selected regular members to also receive training. All members, regardless of the type of training their iddir leaders were assigned to, received training $\mathrm{A}$. Thus the element that was randomized was whether or not the leaders received training type A or training type B.

Iddir leaders were free to choose who they would nominate for the subsequent training. Allowing leaders to select members after training allowed the training to affect both who leaders selected for training and what the leaders discussed with selected members. It may be the case that both are 
important mechanisms by which the training would have an effect on risk-sharing among selected members, with an altered message having little impact if those who were selected could not be changed. As such, asking leaders to select members prior to the training or selecting specific members ourselves could have potentially limited the impact of the training.

We did impose some limits, however, in that the number of people they could select was prescribed. This prescription was somewhat of an artificial construct, but was done in order to distinguish the direct effect of the message received from the indirect effect that may result purely from altering the number of people that were trained.

It may be the case that the number of people trained affects demand. If iddir members spoke with each other about the training after the training ended and if these discussions encouraged demand then being in an iddir in which more people were trained may make it more likely that both selected and non-selected members would buy insurance. In order to test this we randomized the number of members iddir leaders were asked to nominate for the training the following day. This randomization was orthogonal to the training type the iddir leaders received.

In a few cases, the sub-iddirs had more than 100 members and so were also on the randomization list (this federated structure was not recorded at the time of listing). In some of these cases the umbrella and sub iddir were allocated to the same type of training session, but in some cases the large iddir was allocated to one training session and the sub-iddir to another. Given all iddirs are categorized on the basis of the training received within the large iddir as a whole, for these iddirs there is essentially a third possible treatment category: being in a mixed iddir in which some leaders attended one type of training session, and other leaders another.

There are thus essentially three groups of iddirs in our data: those whose leaders attended training $\mathrm{A}$, those whose leaders attended training $\mathrm{B}$, and those whose leaders were mixed between the two sessions. We note here that the probabilities of allocation to treatment varied depending on whether or not an iddir had one of its sub-iddirs on the list. For iddirs with no sub-iddirs on the list, the probability of allocation to treatment $\mathrm{A}$ or $\mathrm{B}$ was 0.5 , whilst for iddirs with one sub-iddir on the list the probability of allocation to treatment A or B was 0.25 and the probability that it would be mixed was 0.5 . We control for this de-facto stratification in the analysis by adding strata dummies to all regressions. Additionally, to focus on the difference between iddirs in which all leaders received training $\mathrm{A}$ and iddirs in which all leaders received training $\mathrm{B}$, we include a dummy for iddirs that received the mixed treatment.

Aside from the difference in framing and content there was no other difference between the sessions. Each trainer conducted training sessions of each type to ensure that results are not driven by trainer effects. At the end of each training session iddir leaders were given the same demand schedules for their members to fill. While the training sessions were carried out by a team of trainers purposely hired by the research team, the demand forms were collected by NISCO staff. The collection of the demand forms took place approximately two weeks after the training sessions. Policies were issued on the basis of these demand forms.

Our randomization design thus allows us to test two things: first, whether training iddir leaders on sharing risk increases demand for insurance, and second, whether the number of ordinary members trained affects demand.

We can also explore the mechanisms by which training iddir leaders on sharing risk may increase demand. As described in the conceptual framework training B could increase demand for insurance by increased risk-sharing among selected members of the iddir. Increased risk-sharing could result from either (i) selection of members already actively engaged in risk-sharing for training, and/or (ii) increased risk-sharing activity among those trained. It is also conceivable that the risk-sharing message did not directly alter risk-sharing among selected members, but provided one additional message in favor of insurance that increased enthusiasm for the insurance products, 
indirectly encouraging insurance purchases. To explore these mechanisms we test whether there were differences in the levels of discussions in iddirs assigned to training A or B, or differences in reported risk-sharing behavior. Whilst differences in post-training discussions do not distinguish which mechanism is at work, evidence of increased risk-sharing in training B iddirs would indicate that it is the nature of this additional message that alters demand.

\subsection{Verifying randomization and testing compliance}

We use two data sources in this paper: a baseline survey of iddirs conducted in December 2009 and January 2010; and data collected in a household survey conducted in June and July 2010. The sampling frame of the household survey was constituted by the full memberships of iddirs that took part in the training exercises. We randomly sampled iddir members whereby we oversampled farmers that had taken part in the training exercises. From a total of 333 respondents, 204 took part in the training. The sample is representative of all iddirs, but without weighting it is not representative at the individual level. However, given our randomization, our interest is on differential impacts between different training sessions, so this is less of a problem.

Tables 2 and 3 describe the sample. We use the data in the baseline survey of iddirs and characteristics of members collected in the household survey that are unlikely to have changed as a result of the training (characteristics of the household head, land ownership etc.) to test whether characteristics of groups, their leaders and their members were balanced across allocation to training type. Table 3 presents results comparing iddirs whose leaders were allocated to training B to the other iddirs. A similar table in the appendix presents results comparing iddirs whose leaders were allocated to be split across training sessions ("mixed" iddirs) to other iddirs. We find that there are few differences across treatments in any baseline characteristics of groups or their leaders and members. Of 39 variables tested, only 2 are significantly different at $5 \%$ or less.

To test compliance with the training type allocation we compare attendance during the training sessions with the initial randomization. There was no particular order to the training sessions (the order of training session A and B was randomized within kebeles), and there was no advertisement about the type of training session that was to be offered (this information was not shared with the person making the appointments). As such we do not have cause to believe that there was any endogenous choice represented in iddir-leaders choosing which day to attend training (in fact we find that only two iddirs had all of their leaders attend on the wrong day). However, we would be more concerned that there is a difference between iddirs in which the leadership chose to split themselves between training (when they were selected to attend together), and iddirs in which the leadership attended the training together.

In two kebeles the training allocations were erroneously disregarded. We do not have cause to believe that there was anything particular about the places in which these sessions were conducted as this mistake happened only in the kebeles visited by one team, the teams were randomly assigned to kebeles and this team made the same mistake in all of their sessions in which no other member of the research team accompanied them. We exclude these kebeles from the analysis.

Table 4 assesses the degree of compliance with initial training allocation in the remaining kebeles for iddirs included in the household survey. As the table indicates, there was very little noncompliance, non-compliance rates were only $8 \%$. Out of 71 iddirs, 6 attended the wrong training session: 1 iddir switched from A to B, 1 switched from mixed to B, 1 switched from A to mixed and 3 switched from B to mixed. To ensure our results are robust to any non-compliance, we use initial training to estimate the intent to treat (ITT) effect, and use the initial allocation as an instrument for actual training.

On completion of their training, iddir leaders were asked to select a certain number of members 
from their iddir to attend a training course about the insurance the following day. Each iddir was given a randomly determined number of members to attend the course the following day. In table 5 we compare the number assigned with the number that showed up and assess whether there is any systematic deviation in the number of people that attended.

We find that the number of members assigned to attend the training session the following day does predict the number of people that turned up the following day, but we also see that there were systematic deviations depending on the type of training the leadership of the iddir had received. In particular we see that the number of people attending is higher when the iddir leadership had received training B. This could reflect a higher level of enthusiasm among iddir leaders about the insurance products after having received the training. ${ }^{4}$ In all regressions we use the number of members assigned to attend training.

\section{Basic results}

Basic data on take-up among the three iddir types for both trained and untrained farmers included in the baseline survey is presented in table 6. The data show high demand for insurance among farmers who had heard about the policy. We find that across all sampled farmers $22 \%$ had purchased a policy, and that among those that were trained take up was 36\%. Take-up was much lower, just $2 \%$, among those that were not trained.

We asked farmers directly why they did or did not purchase insurance and found that the main reason given for purchasing insurance was to protect their family from crop losses (25 percent of households) whilst the main reason for not purchasing insurance was not knowing about it (30 percent of households). Other significant responses were wanting to try a new product to see how it worked (6 percent), wanting to do what others were doing ( 7 percent) and wanting to wait and see how it fared for others before buying it ( 5 percent). Price was mentioned as a constraint by only 1 percent of households. In table 7 we present results from a correlation of insurance purchase decisions and individual characteristics and confirm that receiving training is highly correlated with an insurance purchase. We also find that households with smaller land holdings, with younger household heads who hold official positions are more likely to purchase and that purchases are correlated with being impatient and believing in the honesty of others.

Table 6 also explores whether take-up varies across training types. While take-up was 18\% among sampled members of type-A iddirs, demand for insurance among sampled members of iddirs whose leaders had received training that emphasized the role of groups is $27 \%$, nine percentage points or $50 \%$ higher.

We test this formally by estimating the intent to treat (ITT) as follows:

$$
d_{i j}=\alpha+\beta_{g} g_{j}+\beta_{n} n_{j}+\varepsilon_{i j}
$$

where $d_{i j}$ is a measure of demand for individual $i$ in iddir $j, g_{j}$ indicates the training that leaders of iddir $j$ were allocated to, and $n_{j}$ is the number of ordinary members that leaders were asked to select for training. Trained farmers were purposively selected (iddir leaders and those they nominated) so we focus our analysis on the impact of the element of the training that was random - the allocation of the iddir leaders to training type and the number of members leaders were requested to select for subsequent training.

We are interested in the impact of training type on demand, $\beta_{g}$. We include a dummy for those iddirs that received mixed training such that a test of the significance of $\beta_{g}$ is a test of whether

\footnotetext{
${ }^{4}$ We note that there is no difference in the number of leaders that attended training between training sessions $\mathrm{A}$ and training sessions B. The p-value of a t-test of equality is 0.415 .
} 
iddirs in which all leaders received training B are different from iddirs in which all leaders received training A. Strata dummies are also included in the estimation given random allocation included stratification of iddirs. Coefficients on the mixed training dummy and strata dummies are not reported.

Results are presented in table 8. In columns 1 and 2 we present regression results at the iddir level. The dependent variable in column 1 is the proportion of sampled farmers in the iddir that reported purchasing a policy. In column 2 the dependent variable is whether or not any sampled farmer in the iddir reported purchasing a policy. In columns 3 and 4 we present results at the household level. In column 3 no additional regressors are included, in column 4 characteristics of households that were collected after training but unlikely to have changed over time are included in order to increase precision of the estimates of the treatment effects. An F-test that all characteristics are jointly significant, indicates that the null hypothesis of joint insignificance can be rejected $(\mathrm{F}(9$, $\left.69)=4.16^{* * *}\right)$. District fixed effects are also added for the same reason. In columns 3 and 4 we correct for correlation across individuals at the level of the iddir, the unit of randomization, by adjusting standard errors for clustering within an iddir.

In all specifications we see that allocation of leaders to training B substantially increased demand with estimates of $\beta_{g}$ positive and significant in all columns. This suggests that emphasizing the role of groups in mediating insurance substantially increases take-up. Demand was also higher in iddirs which were assigned more members for subsequent training. This is not surprising given purchase rates were much higher among those who were trained (table 6) than among those who were not.

Taking the iddir level results in column 2, we see that the impact of training B was quite sizeable; increasing the probability that someone in the iddir would buy insurance by 29 percent. We also instrument actual training received using training allocation as an instrument. Specifically the estimation strategy used is:

$$
d_{i j}=\alpha+\beta_{\gamma} \widehat{\gamma_{j}}+\beta_{n} n_{j}+\varepsilon_{i j}
$$

where $\widehat{\gamma_{j}}$ is the estimate derived from the following equation:

$$
\gamma_{j}=a+\beta_{g} g_{j}+\beta_{n} n_{j}+\epsilon_{i j}
$$

The IV estimates are presented in columns 5 to 8 of table 8 . The estimates suggest the average treatment effects are robust to the handful of switches between training that we observed. The coefficient on the treatment B dummy is of a similar order of magnitude and is significant when additional regressors are included.

In table 9 we explore two further measures of demand for insurance: number of policies purchased, and total value insured. We present ITT and IV estimates for these alternative outcomes, and find that trained farmers in training-B iddirs purchased more policies and insured a higher value of exposure.

These results suggest that leader training which encourages risk sharing, and frames insurance as something that can benefit the group, increases demand. In the following section we explore how this training increased demand.

\section{$5 \quad$ Further exploration}

As table 6 indicates there are three types of farmers in our survey: leaders who took part in leader training sessions (either A or B), members who attended member-training sessions (A) and members who did not take part in any training. Thus far the analysis has highlighted that iddirs 
with a leadership that received training $B$ had higher take-up than iddirs with a leadership that received training A. We now examine whether treatment B iddirs saw increased demand among trained or untrained members of the group and among the trained members, whether it increased demand more for leaders or members.

Selection into training was not random-iddir leaders were selected to attend the first training session and they chose who would attend the following session. The impact of training cannot be assessed, but it is informative to look at who increased their demand as a result of the messages given to leaders, whether this increased demand among leaders themselves, those they selected to attend training (either through who they selected or discussions they had with them) or those who had not attended training. Table 6 suggests that training that emphasized sharing encouraged take-up among members and leaders alike, but we test this formally in table 10.

Table 10 underscores the finding that training is strongly correlated with demand. The results also indicate that when iddir leadership received training B, take-up among the trained in that iddir (both among the leadership and the ordinary trained members who had received training A) increased much more than take-up among the non-trained. In fact the results suggest that, among the non-trained, the type of training received by the iddir leadership did not affect demand. Increased take-up resulted solely from those trained-the leaders themselves and the ordinary members.

A further interaction of iddir leadership, receipt of training and iddir type shows that iddir leaders and ordinary members were not equally likely to increase demand. The small number of iddir leaders in our sample, makes the estimate of the impact of training on iddir leaders imprecise, but the results suggest that the training had a larger impact on ordinary members than on iddir leaders (although the size of the impact on iddir leaders was also sizable). This suggests that the messages communicated in the leadership training sessions had an impact on trained ordinary members. It suggests that either the way ordinary members were selected by their leaders or the discussions that leaders had with these members, or risk-sharing implemented by these members encouraged higher take-up.

In the following subsections we examine the evidence we have on how training had an impact. We examine whether the number or type of individuals selected in training B iddirs were different, and whether trained individuals in training B iddirs were more likely to discuss the training and with whom. Finally we explore evidence for increased risk sharing among selected members of treatment B iddirs.

First, however, we examine whether providing training B to leaders resulted in better training and improved understanding of the products being offered.

\subsection{Group training was a better training}

A potential concern in our analysis is the possibility that training B might have been different in other ways, beyond the emphasis on the benefits of sharing. While training A and B only differed in the framing and the discussion of how to make decisions in the last half hour of the training, we would like to test whether the different nature of the discussion within the session (or that resulted from the session) might have led to an enhanced understanding of the product.

In table 11 we explore this possibility. We analyze the effect of training type on understanding of two aspects of the insurance that were emphasized in the training: the concept of millimeters and the concept of basis risk. We would expect understanding of both to be positively affected by training. However, if randomized training sessions did not differ in quality of training, respondents in type-B iddirs should not have a better understanding of these two issues than respondents in type-A iddirs.

To measure understanding of millimeters we asked whether farmers had ever heard of millimeters 
and how many millimeters were likely to fall in an hour of heavy rain. Using the combined response, we find that those that were trained were twice as likely to know about millimeters as those that were not trained. However, this could indicate that more knowledgeable farmers were being trained rather than that the training was effective.

We test differences across training types and find that the type of training had no effect on understanding (columns 1 and 2 of table 11). Measuring whether respondents understood that basis risk exists is more difficult. We asked the respondent to consider a hypothetical situation in which he had bought insurance and experienced downside basis risk (experienced bad yields whilst the weather station recorded a good reading). We then asked the respondent to state whether or not he would purchase insurance again in the following year. If the respondent had understood that basis risk exists one could argue that his response would be less affected by the description of this scenario. We test this in columns 3 and 4 of table 11. For both of these measures we find that the type of training received did not impact understanding on these two issues.

\subsection{Discussion of insurance}

The number of members the iddir was requested to select for training is a significant determinant of take-up in all specifications estimated thus far. Receiving training is the single largest determinant of whether or not an individual purchased insurance and the probability that an individual received training increased with the number of people the iddir was requested to select. However, there is another possible explanation for why demand increased with the number trained: if iddir members spoke with each other about the training after the training ended and if these discussions encouraged demand then being in an iddir in which more people were trained may have increased demand in this manner. We test for the presence of this type of externality by looking at whether the number of people trained in an iddir had an impact on an individuals demand after controlling for receipt of training. We find that its significance is reduced, but it still had some impact with a p-value of 0.104 (results presented in column 3 of table 10) indicating some positive externality resulting from the number of members being trained. To the extent that training type B increased the number of iddir members that were trained, training type B may have resulted in increased take-up in this manner.

We further explore the effect of training type on how much trained farmers spoke to others about the insurance policies by examining survey responses on whether trained members spoke to others about the insurance and the number of people spoken to. Only farmers that were in the training were asked these questions, so the individual level regression is restricted to trained farmers. We find all treatment variables are insignificant.

We also test whether awareness of non-trained farmers about the insurance policies being sold was higher in type B iddirs. This gives some indication of whether the increased discussions about the policies in type $\mathrm{B}$ iddirs were between trained and non-trained farmers resulting in higher awareness of others about the policy. We find that they do not. This suggests that the increased discussions in type $\mathrm{B}$ iddirs were not with non-trained farmers. This corresponds to the finding that type B training did not increase purchases among non-trained farmers.

Although there is some evidence of positive externalities from training members, we find little direct evidence of increased discussions among members.

\subsection{Selection of members for training}

Training B encouraged iddir leaders to ensure more members attended the member-training held

on the following day. It could be the case that iddir leader training also had an effect on who 
was chosen for training, not just how many people were chosen. We compare observed baseline characteristics of those selected for training by B-leaders to those selected for training by non-B leaders. We use the same variables used in table 3 which cover aspects of human, social and physical capital. These are characteristics that will not have been affected by the intervention. Results are presented in table 12 and show that there are no observable differences.

However, other characteristics such as an individuals preference for risk, or an individuals predisposition to engage in risk-sharing, may be more likely to affect whether or not an individual was selected by the iddir leadership for training. Without pre-intervention measures of these characteristics it is hard to ascertain whether or not this was the case. However, we present an analysis of post-intervention measures of these characteristics in table 13. We test for differences in risk preference, time preference, and beliefs about the honesty and trustworthiness of others. We find that individuals selected for training in group B iddirs were more likely to believe others to be honest and trustworthy. This could reflect differential selection across training types, but equally we cannot rule out the possibility that this difference is itself an impact of the intervention.

\subsection{Risk-sharing among selected members}

Few untrained farmers purchased insurance, and training B did not encourage increased knowledge or demand of insurance among untrained iddir members. Thus, if training B increased demand by encouraging increased risk-sharing of risks not covered by the policy, it is likely that it was taking place initially amongst sub-groups within the iddir, and not the iddir membership as a whole.

If higher demand in type B iddirs is driven by increased complementary risk sharing, we would expect to see evidence of higher levels of risk-sharing in type B iddirs. Risk-sharing could take the form of more gifts or loans being received by iddir members to manage shortfalls in food consumption or other sources of income shocks (such as health shocks). We test whether individuals in type B iddirs were more likely to report receiving gifts from individuals or loans for food consumption or health expenses in the 12 months prior to the survey. Results for these tests are presented in table 14 .

We do find evidence of higher levels of gifts and consumption loans being received among members of type B iddirs, particularly consumption loans. The result could reflect two things: (i) that those who were more engaged in risk sharing (as evidenced by higher receipts of gifts and loans) were more likely to be selected for training by leaders in type B iddirs, or (ii) that the intervention encouraged increased risk sharing among selected members. Either mechanism is consistent with the idea that encouraging risk sharing increased take-up. Given most of the reference period fell prior to the intervention, it is perhaps most likely to be selection that is driving the difference.

To further explore evidence consistent with the hypothesis that increased risk sharing caused increased insurance purchases in type B iddirs we look at the degree of correlation between purchases of members in the same iddir. If the difference in training had an effect by increasing risk sharing we may expect that take-up would not just be higher among members in training B iddirs, but that training would be more correlated among members in training B iddirs. If the payout will be dissipated via the demands for risk-sharing of the network, a given member has more of an incentive to purchase insurance if others do so as well. In contrast, take-up in iddirs where risk sharing was not encouraged may be more of an individual decision. ${ }^{5}$ The variation in take-up that is explained by variation across iddirs is much higher in type B iddirs than in type A iddirs (the adjusted R-squared of a regression of take-up on iddir dummies is 0.09 in type B iddirs and -0.03 in type A iddirs). We test whether there was increased variance of take-up among training

\footnotetext{
${ }^{5}$ We are grateful to a reviewer for pointing this out.
} 
B iddirs compared to training A iddirs. Given we only surveyed some members of each iddir we are somewhat limited in the extent to which we can test this, but we do find that the variance of demand is marginally higher among training B iddirs. The standard deviation of demand among training B iddirs is 0.30 whilst the standard deviation of demand among training A iddirs is 0.24. A test that the standard deviation of take up in training B is higher than the standard deviation of take up in training A has a p-value of 0.11 .

We do not find that members of type B iddirs were more likely to make a joint insurance purchase decision or to share policies. These questions were only asked to those farmers that bought a policy, so the sample is quite small (74 farmers), and-perhaps because of the small sample size - -we found no effect (results not reported). However it may also reflect the fact that increased risk-sharing does not necessarily entail farmers sharing insurance policies.

\section{Conclusions}

In this paper, we report the results from a first attempt to market weather insurance products to informal risk-sharing groups, and find that demand among trained members was substantially increased when groups were exposed to training that encouraged sharing of insurance within groups.

We propose that one mechanism for this higher level of take-up may come from the ability of groups to mitigate some of the basis risk inherent in these products. We provide a theoretical proof that shows that, under quite general conditions, risk-sharing and index insurance are complementary with increased access to one driving up demand for the other. We also show that this is quite different to the relationship between risk-sharing and indemnity insurance, where no such complementary relationship exists.

We found that leaders that had received training on how policies and payouts could be shared among group members encouraged more members to attend a subsequent training session. Additionally, when the leadership was trained on sharing policies and payouts increased risk-sharing was reported among members. The results also suggest that if farmers are increasing informal risk sharing as a result, it is being done in small groups of selected farmers.

\section{References}

Arnott, R. and J. Stiglitz (1991). Moral Hazard and Nonmarket Institutions: Dysfunctional Crowding Out of Peer Monitoring? The American Economic Review 81(1), 179-190.

Attanasio, O. and J. Rios-Rull (2000). Consumption smoothing in island economies: Can public insurance reduce welfare? European Economic Review 44 (7), 1225-1258.

Barnett, B. J. and O. Mahul (2007). Weather index insurance for agriculture and rural areas in lower income countries. American Journal of Agricultural Economics 89, 1241-1247.

Cai, H., Y. Chen, H. Fang, and L.-A. Zhou (2009). Microinsurance, trust and economic development: Evidence from a randomized natural field experiment. NBER Working Paper No. 15396.

Clarke, D. (2011a). Reinsuring the poor: Group microinsurance design and costly state verification. University of Oxford Department of Economics Discussion Paper 573.

Clarke, D. (2011b). A theory of rational demand for index insurance. University of Oxford Department of Economics Discussion Paper 572. 
Coate, S. and M. Ravallion (1993). Reciprocity Without Commitment. Journal of Development Economics 40(1), 1-24.

Cole, S. A., X. Gine, J. Tobacman, P. B. Topalova, R. M. Townsend, and J. I. Vickery (2009). Barriers to household risk management: Evidence from India. Harvard Business School Finance Working Paper No. 09-116.

Dercon, S. and L. Christiaensen (2011). Consumption risk, technology adoption and poverty traps: Evidence from Ethiopia. Journal of Development Economics.

Dercon, S., J. W. Gunning, and A. Zeitlin (2011). The demand for insurance under limited credibility: Evidence from Kenya. Mimeo, University of Oxford.

Dercon, S., J. D. Weerdt, T. Bold, and A. Pankhurst (2006). Group-based funeral insurance in Ethiopia and Tanzania. World Development 34(4), 685-703.

Eeckhoudt, L. and H. Schlesinger (2006). Putting risk in its proper place. The American Economic Review, 280-289.

Giné, X., R. Townsend, and J. Vickery (2008). Patterns of rainfall insurance participation in rural India. World Bank Econ Rev 22(3), 539-566.

Giné, X. and D. Yang (2009). Insurance, credit, and technology adoption: Field experimental evidence from Malawi. Journal of Development Economics.

Hill, R. V. and M. Robles (2011). Flexible insurance for heterogeneous farmers: Results from a small-scale pilot in Ethiopia. IFPRI Discussion Paper.

Ibarra, H. (2004). Self-Insurance Funds in Mexico. In E. Gurenko (Ed.), Catastrophe Risk and Reinsurance: A Country Risk Management Perspective, Chapter 18.

Kimball, M. (1990). Precautionary saving in the small and in the large. Econometrica: Journal of the Econometric Society, 53-73.

Kimball, M. (1992). Precautionary motives for holding assets. In P. Newman, M. Milgate, and J. Falwell (Eds.), New Palgrave dictionary of money and finance, Volume 3, pp. 158-161.

Meherette, E. (2009). Providing weather index and indemnity insurance in Ethiopia. Brief 8, 2020 Focus 17, International Food Policy Research Institute.

Mobarak, A. and M. Rosenzweig (2012). Selling formal insurance to the informally insured. Yale University Economic Growth Center Discussion Paper (1007).

Skees, J., P. Hazell, and M. Miranda (1999). New approaches to crop yield insurance in developing countries. IFPRI Discussion Paper, EPTD-55. 


\section{Tables}

Table 2: Descriptive statistics of household sample

\begin{tabular}{lcc}
\hline & Mean & Standard deviation \\
\hline Purchased insurance (yes=1) & 0.23 & 0.42 \\
Number of insurance policies bought & 0.30 & 0.63 \\
Value of insurance bought (Birr) & 18.01 & 39.95 \\
Understands millimeters (yes=1) & 0.32 & 0.47 \\
Understands basis risk (yes=1) & 0.71 & 0.45 \\
Amount to wait 1 month for 100 Birr (Birr) & 199.93 & 141.58 \\
Constant Relative Risk Aversion & 1.21 & 1.03 \\
Believes others are honest (Likert scale*) & 5.07 & 1.31 \\
Believes others can be trusted (Likert scale*) & 5.05 & 1.28 \\
Received a gift in the last 12 months (yes=1) & 0.07 & 0.25 \\
Received a consumption loan (yes=1) & 0.11 & 0.31 \\
Received a gift or consumption loan (yes=1) & 0.17 & 0.38 \\
\hline \multicolumn{2}{c}{ * Likert scale: 1 = strongly disagree, } & $7=$ strongly agree
\end{tabular}

${ }^{*}$ Likert scale: $1=$ strongly disagree, $\ldots, 7=$ strongly agree 
Table 3: Test of balance between iddirs in which leader was allocated to training B and others

\begin{tabular}{|c|c|c|c|}
\hline & $\begin{array}{c}\text { Leader received } \\
\text { Training A }\end{array}$ & $\begin{array}{c}\text { Leader received } \\
\text { Training B }\end{array}$ & $\begin{array}{c}\text { Test of difference } \\
\text { (P-value) }\end{array}$ \\
\hline \multicolumn{4}{|l|}{ Group characteristics (77 groups, 24 type B) } \\
\hline Year of creation & 1979 & 1977 & 0.71 \\
\hline Number of members & 182 & 184 & 0.93 \\
\hline Share that are women & 0.05 & 0.06 & 0.93 \\
\hline Requires regular payments & 0.69 & 0.94 & 0.05 \\
\hline Annual regular payments (Birr) & 30 & 43 & 0.05 \\
\hline Number of regular payments & 15 & 16 & 0.95 \\
\hline Entry fee (Birr) & 141 & 100 & 0.28 \\
\hline Payout on adult death (Birr) & 1090 & 891 & 0.19 \\
\hline Prop. of members that are farmers & 0.96 & 1.00 & 0.26 \\
\hline \multicolumn{4}{|l|}{ Leader characteristics (68 leaders, 21 type B) } \\
\hline Age & 39.23 & 41.67 & 0.31 \\
\hline Gender $(1=$ female $)$ & 0.02 & 0.00 & 0.51 \\
\hline Can read (1=yes) & 0.73 & 0.62 & 0.47 \\
\hline Can write $(1=$ yes $)$ & 0.73 & 0.62 & 0.47 \\
\hline Education (years) & 5.26 & 5.10 & 0.86 \\
\hline Born in this kebele $(1=$ yes $)$ & 0.96 & 1.00 & 0.34 \\
\hline Holds an official position ( $1=$ yes $)$ & 0.28 & 0.33 & 0.64 \\
\hline Parents held official position (1=yes) & 0.23 & 0.14 & 0.40 \\
\hline Relatives hold an official position ( $1=$ yes) & 0.57 & 0.43 & 0.27 \\
\hline Member of a cooperative $(1=$ yes $)$ & 0.51 & 0.67 & 0.24 \\
\hline Number of iddirs of which a member & 2.83 & 3.10 & 0.40 \\
\hline Log of land owned (timads) & 1.24 & 1.26 & 0.92 \\
\hline Own a mobile phone ( $1=$ yes $)$ & 0.40 & 0.38 & 0.86 \\
\hline Member of an eqqub ( $1=$ yes $)$ & 0.09 & 0.00 & 0.17 \\
\hline Has a bank account (1=yes) & 0.04 & 0.05 & 0.93 \\
\hline \multicolumn{4}{|l|}{ Member characteristics(224 members, 84 type B) } \\
\hline Age & 39.99 & 39.88 & 0.94 \\
\hline Gender $(1=$ female $)$ & 0.02 & 0.04 & 0.53 \\
\hline Can read $(1=$ yes $)$ & 0.58 & 0.62 & 0.53 \\
\hline Can write $(1=$ yes $)$ & 0.57 & 0.64 & 0.38 \\
\hline Education (years) & 4.56 & 4.77 & 0.69 \\
\hline Born in this kebele $(1=$ yes $)$ & 0.96 & 0.96 & 0.79 \\
\hline Holds an official position ( $1=$ yes $)$ & 0.25 & 0.19 & 0.31 \\
\hline Parents held official position (1=yes) & 0.18 & 0.15 & 0.63 \\
\hline Relatives hold an official position ( $1=$ yes) & 0.50 & 0.43 & 0.28 \\
\hline Member of a cooperative $(1=$ yes $)$ & 0.51 & 0.38 & 0.06 \\
\hline Number of iddirs of which a member & 2.19 & 2.33 & 0.24 \\
\hline Log of land owned (timads) & 1.03 & 1.05 & 0.93 \\
\hline Own a mobile phone ( $1=$ yes $)$ & 0.33 & 0.27 & 0.37 \\
\hline Member of an eqqub ( $1=$ yes $)$ & 0.09 & 0.08 & 0.94 \\
\hline Has a bank account ( $1=$ yes $)$ & 0.03 & 0.04 & 0.77 \\
\hline
\end{tabular}


Table 4: Actual and intended training received by iddir leader(number of iddirs covered in household survey)

\begin{tabular}{llccc} 
& & \multicolumn{3}{c}{ Intended } \\
& & Training A & Training B & Mixed \\
\hline Actual & Training A & 37 & 0 & 0 \\
& Training B & 1 & 18 & 1 \\
& Mixed & 1 & 3 & 9 \\
\hline
\end{tabular}


Table 5: Number of ordinary members attending training

(1)

Number attending training
(2)

Difference between number attending and number allocated
Number of members allocated for training $\quad 0.292 * *$

Iddir in which leader received training B

(0.112)

Constant

$2.441 * * *$

(0.812)

Observations

70

0.213

Standard errors in parentheses $* * * p<0.01, * * p<0.05, * p<0.1$
2.139*

(1.277)

$-1.502$

(0.992)

70

0.106 
Table 6: Purchase rates as a percentage of surveyed households

\begin{tabular}{lccc}
\hline & Training A & Training B & Mixed \\
\hline Leader & 0.36 & 0.50 & 0.18 \\
Trained member & 0.26 & 0.43 & 0.58 \\
Untrained member & 0.02 & 0.02 & 0.00 \\
\hline Total & 0.18 & 0.27 & 0.26 \\
\hline
\end{tabular}

Training A (B) means that iddir leadership was trained in session A (B); trained members were all trained in A. 
Table 7: Regression of demand for insurance on potential correlates

\begin{tabular}{lc}
\hline Time preference & $-0.0002\left(0.0001^{*}\right)$ \\
Constant Relative Risk Aversion & $0.01(0.02)$ \\
Believes others to be honest & $0.03\left(0.02^{* *}\right)$ \\
Received a gift or loan & $0.04(0.07)$ \\
Log of land owned & $-0.05\left(0.01^{* * *}\right)$ \\
Age & $-0.003(0.002)$ \\
Education in years & $-0.01(0.01)$ \\
Female & $0.04(0.13)$ \\
Holds an official position & $0.12\left(0.05^{* * *}\right)$ \\
Parents held an official position & $-0.17\left(0.05^{* * *}\right)$ \\
Household received training & $0.35\left(0.05^{* * *}\right)$ \\
Constant & $0.09(0.13)$ \\
\hline Number of observations & 283 \\
R-squared & 0.2714 \\
\hline
\end{tabular}

Standard errors in parentheses ${ }^{* * *} \mathrm{p}_{i} 0.01,{ }^{* *} \mathrm{p}_{i} 0.05,{ }^{*} \mathrm{p}_{i} 0.1$. District fixed effects included but not shown. 
Table 8: Estimates of the impact of treatment on insurance demand (ITT and IV)

\begin{tabular}{|c|c|c|c|c|c|c|c|c|}
\hline & \multicolumn{4}{|c|}{ Intent to Treat (ITT) } & \multicolumn{4}{|c|}{ Instrumental Variable (IV) } \\
\hline & $\begin{array}{c}\text { (1) } \\
\text { Average } \\
\text { demand } \\
\text { in group }\end{array}$ & $\begin{array}{c}\text { (2) } \\
\text { Anyone in } \\
\text { group } \\
\text { purchased }\end{array}$ & $\begin{array}{l}\text { Individual } \\
\text { purchased }\end{array}$ & $\begin{array}{l}\text { Individual } \\
\text { purchased }\end{array}$ & $\begin{array}{c}\text { (5) } \\
\text { Average } \\
\text { demand } \\
\text { in group }\end{array}$ & $\begin{array}{c}\text { (6) } \\
\text { Anyone in } \\
\text { group } \\
\text { purchased }\end{array}$ & $\begin{array}{c}\text { (7) } \\
\text { Individual } \\
\text { purchased }\end{array}$ & $\begin{array}{c}\text { (8) } \\
\text { Individual } \\
\text { purchased }\end{array}$ \\
\hline Training B & $\begin{array}{l}0.154 * * \\
(0.069)\end{array}$ & $\begin{array}{l}0.294 * * \\
(0.133)\end{array}$ & $\begin{array}{l}0.113^{*} \\
(0.062)\end{array}$ & $\begin{array}{c}0.133^{* *} \\
(0.054)\end{array}$ & $\begin{array}{c}0.167^{* *} \\
(0.081)\end{array}$ & $\begin{array}{c}0.314^{* *} \\
(0.155)\end{array}$ & $\begin{array}{c}0.115 \\
(0.079)\end{array}$ & $\begin{array}{l}0.159 * * \\
(0.065)\end{array}$ \\
\hline $\begin{array}{l}\text { Number allocated } \\
\text { to training }\end{array}$ & $\begin{array}{l}0.020 * * \\
(0.008)\end{array}$ & $\begin{array}{c}0.021 \\
(0.016)\end{array}$ & $\begin{array}{l}0.013^{*} \\
(0.007)\end{array}$ & $\begin{array}{l}0.014^{*} \\
(0.008)\end{array}$ & $\begin{array}{l}0.020 * * \\
0.167 * *\end{array}$ & $\begin{array}{c}0.020 \\
0.314^{* *}\end{array}$ & $\begin{array}{c}0.013^{*} \\
0.115\end{array}$ & $\begin{array}{c}0.014^{*} \\
0.159 * *\end{array}$ \\
\hline Constant & $\begin{array}{c}0.073 \\
(0.059)\end{array}$ & $\begin{array}{c}0.329 * * * \\
(0.113)\end{array}$ & $\begin{array}{c}0.113^{* *} \\
(0.049)\end{array}$ & $\begin{array}{c}0.119 \\
(0.123)\end{array}$ & $\begin{array}{c}0.067 \\
(0.061)\end{array}$ & $\begin{array}{c}0.317^{* * *} \\
(0.117)\end{array}$ & $\begin{array}{l}0.097^{*} \\
(0.050)\end{array}$ & $\begin{array}{c}0.108 \\
(0.126)\end{array}$ \\
\hline Basic characteristics & No & No & No & Yes & No & No & No & Yes \\
\hline District fixed effects & No & No & No & Yes & No & No & No & Yes \\
\hline Observations & 70 & 70 & 290 & 288 & 70 & 70 & 290 & 288 \\
\hline R-squared & 0.134 & 0.100 & 0.027 & 0.126 & 0.137 & 0.096 & 0.005 & 0.129 \\
\hline
\end{tabular}

Standard errors in parentheses $* * * p<0.01,{ }^{* *} p<0.05,{ }^{*} p<0.1$.

Training $B$ means that iddir leadership received training $B$ 
Table 9: Estimates of the impact of treatment on the number and value of policies bought (ITT and IV)

\begin{tabular}{|c|c|c|c|c|}
\hline & \multicolumn{2}{|c|}{ Number of policies purchased } & \multicolumn{2}{|c|}{ Value of policies purchased } \\
\hline & (1) & (2) & (3) & (4) \\
\hline & ITT & IV & ITT & IV \\
\hline \multirow[t]{2}{*}{ Training B } & $0.197 * *$ & $0.231 * *$ & $9.906 * *$ & $11.473 * *$ \\
\hline & $(0.078)$ & $(0.095)$ & $(4.382)$ & $(5.260)$ \\
\hline \multirow[t]{2}{*}{ Number allocated to training } & $0.026^{* *}$ & $0.025^{* *}$ & $1.446^{* *}$ & $1.425^{* *}$ \\
\hline & $(0.012)$ & $(0.012)$ & $(0.704)$ & $(0.714)$ \\
\hline \multirow[t]{2}{*}{ Constant } & 0.033 & 0.014 & 3.397 & 2.371 \\
\hline & $(0.182)$ & $(0.186)$ & $(10.420)$ & $(10.378)$ \\
\hline Basic characteristics & Yes & Yes & Yes & Yes \\
\hline District fixed effects & Yes & Yes & Yes & Yes \\
\hline Observations & 289 & 289 & 284 & 284 \\
\hline R-squared & 0.091 & 0.092 & 0.082 & 0.082 \\
\hline
\end{tabular}

Robust standard errors in parentheses *** $p<0.01, * * p<0.05, * p<0.1$

Training B means that iddir leadership received training B 
Table 10: Estimating the impact of training on insurance purchases by iddir leaders, trained members and untrained members (ITT)

\begin{tabular}{lccc}
\hline & $(1)$ & $(2)$ & $(3)$ \\
& & & \\
Iddir leader & $0.354^{* * *}$ & $0.367^{* * *}$ & \\
& $(0.098)$ & $(0.105)$ & \\
Trained ordinary member & $0.238^{* * *}$ & $0.222^{* * *}$ & \\
& $(0.058)$ & $(0.054)$ & \\
Training B * iddir leader & 0.153 & 0.108 & \\
& $(0.144)$ & $(0.148)$ & \\
Training B * trained ordinary member & 0.198 & $0.235^{* *}$ & \\
& $(0.126)$ & $(0.112)$ & $0.186^{*}$ \\
Training B * untrained member & 0.037 & 0.018 & $(0.098)$ \\
& $(0.034)$ & $(0.035)$ & 0.017 \\
Training B & & & $(0.010)$ \\
& & & $0.205^{* *}$ \\
Number allocated training & $0.013^{*}$ & $0.012^{*}$ & $(0.080)$ \\
& $(0.007)$ & $(0.007)$ & \\
Constant & -0.052 & 0.169 & No \\
& $(0.034)$ & $(0.106)$ & 172 \\
& & & 0.0508 \\
\hline Basic characteristics & No & Yes & \\
District fixed effects & No & Yes & \\
Observations & 290 & 288 & \\
R-squared & 0.232 & 0.317 & \\
\hline Robust standard & & \\
\hline
\end{tabular}

Robust standard errors in parentheses ${ }^{* * *} p<0.01,{ }^{* *} p<0.05,{ }^{*} p<0.1$

Training B means that iddir leadership received training $B$ 
Table 11: Estimating the impact of training on understanding of millimeters and basis risk

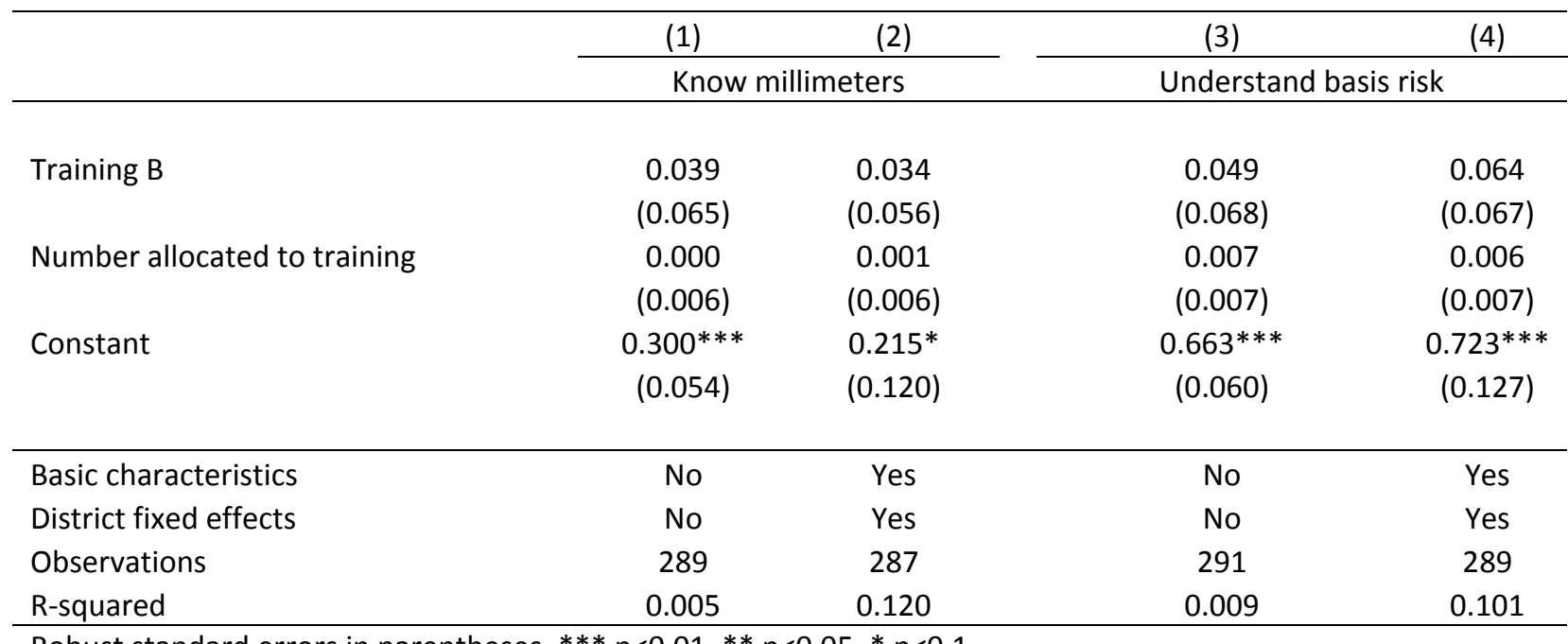

Robust standard errors in parentheses. ${ }^{* * *} p<0.01,{ }^{* *} p<0.05,{ }^{*} p<0.1$

Training B means that iddir leadership received training B 
Table 12: Testing for differences in means between ordinary members selected for training by leaders who received training $A$ and $B$ respectively

\begin{tabular}{lccc}
\hline & $\begin{array}{c}\text { Members of iddirs in } \\
\text { which leader attended } \\
\text { training A }\end{array}$ & $\begin{array}{c}\text { Members of iddirs in } \\
\text { which leader attended } \\
\text { training A }\end{array}$ & $\begin{array}{c}\text { Test of difference (P } \\
\text { value) }\end{array}$ \\
\hline Age & 41.17 & 42.36 & 0.57 \\
Gender (1=female) & 0.02 & 0.02 & 0.86 \\
Can read (1=yes) & 0.71 & 0.64 & 0.51 \\
Can write (1=yes) & 0.69 & 0.64 & 0.62 \\
Education (years) & 5.39 & 4.55 & 0.30 \\
Born in this kebele (1=yes) & 0.96 & 0.95 & 0.80 \\
Holds an official position (1=yes) & 0.31 & 0.33 & 0.85 \\
Parents held official position (1=yes) & 0.13 & 0.26 & 0.10 \\
Relatives hold an official position (1=yes) & 0.56 & 0.52 & 0.76 \\
Number of iddirs of which a member & 2.41 & 2.48 & 0.71 \\
Leader of other iddir & 0.35 & 0.36 & 0.96 \\
Log of land owned (timads) & 1.09 & 1.29 & 0.55 \\
Own a mobile phone (1=yes) & 0.35 & 0.36 & 0.96 \\
Member of an eqqub (1=yes) & 0.15 & 0.07 & 0.25 \\
Has a bank account (1=yes) & 0.02 & 0.05 & 0.42 \\
\hline
\end{tabular}


Table 13: Estimating differences in attitudes between treatments (ITT)

\begin{tabular}{|c|c|c|c|c|c|c|c|c|}
\hline \multirow{3}{*}{ Training B } & (1) & $(2)$ & (3) & (4) & (5) & $(6)$ & (7) & (8) \\
\hline & \multicolumn{2}{|c|}{ Time preferences } & \multicolumn{2}{|c|}{ Risk preferences } & \multicolumn{2}{|c|}{$\begin{array}{c}\text { Believes others to be } \\
\text { honest }\end{array}$} & \multicolumn{2}{|c|}{$\begin{array}{l}\text { Believes others to be } \\
\text { trustworthy }\end{array}$} \\
\hline & $\begin{array}{l}-19.229 \\
(18.699)\end{array}$ & $\begin{array}{l}-20.753 \\
(16.650)\end{array}$ & $\begin{array}{l}-0.052 \\
(0.155)\end{array}$ & $\begin{array}{l}-0.033 \\
(0.162)\end{array}$ & $\begin{array}{c}0.227 \\
(0.181)\end{array}$ & $\begin{array}{l}0.251^{*} \\
(0.149)\end{array}$ & $\begin{array}{c}0.266 \\
(0.174)\end{array}$ & $\begin{array}{r}0.307^{* *} \\
(0.138)\end{array}$ \\
\hline Constant & $\begin{array}{c}213.889 * * * \\
(15.605)\end{array}$ & $\begin{array}{c}231.859 * * * \\
(33.938)\end{array}$ & $\begin{array}{c}1.215^{* * *} \\
(0.097)\end{array}$ & $\begin{array}{c}1.102 * * * \\
(0.266)\end{array}$ & $\begin{array}{c}4.963 * * * \\
(0.129)\end{array}$ & $\begin{array}{c}4.530 * * * \\
(0.298)\end{array}$ & $\begin{array}{c}4.934 * * * \\
(0.124)\end{array}$ & $\begin{array}{r}4.513^{* * *} \\
(0.290)\end{array}$ \\
\hline $\begin{array}{l}\text { Basic } \\
\text { characteristics } \\
\text { District fixed }\end{array}$ & No & Yes & No & Yes & No & Yes & No & Yes \\
\hline effects & No & Yes & No & Yes & No & Yes & No & Yes \\
\hline Observations & 286 & 284 & 291 & 289 & 291 & 289 & 291 & 289 \\
\hline R-squared & 0.016 & 0.056 & 0.008 & 0.043 & 0.015 & 0.078 & 0.019 & 0.080 \\
\hline
\end{tabular}

Robust standard errors in parentheses ${ }^{* * *} p<0.01,{ }^{* *} p<0.05,{ }^{*} p<0.1$

Training B means that iddir leadership received training B 
Table 14: Estimating differences in risk-sharing between treatments (ITT)

\begin{tabular}{lcccccc}
\hline & $(1)$ & $(2)$ & $(3)$ & $(4)$ & $(5)$ & $(6)$ \\
\cline { 2 - 6 } & \multicolumn{2}{c}{$\begin{array}{c}\text { Received gift or } \\
\text { consumption loan }\end{array}$} & \multicolumn{2}{c}{ Received gift } & \multicolumn{2}{c}{$\begin{array}{c}\text { Received consumption } \\
\text { loan }\end{array}$} \\
\hline \multirow{3}{*}{ Training B } & & & & & & \\
& $0.099^{*}$ & $0.075^{*}$ & 0.007 & -0.007 & $0.093^{*}$ & 0.071 \\
Constant & $(0.057)$ & $(0.045)$ & $(0.049)$ & $(0.052)$ & $(0.054)$ & $(0.045)$ \\
& $0.110^{* * *}$ & $0.398^{* * *}$ & $0.154^{* * *}$ & 0.130 & $0.088^{* * *}$ & $0.335^{* * *}$ \\
& $(0.025)$ & $(0.118)$ & $(0.033)$ & $(0.082)$ & $(0.021)$ & $(0.107)$ \\
\hline Basic characteristics & & & & & & No \\
District fixed effects & No & Yes & No & Yes & Yes \\
Observations & 291 & 289 & 291 & 289 & 291 & 289 \\
R-squared & 0.015 & 0.104 & 0.008 & 0.039 & 0.017 & 0.085 \\
\hline
\end{tabular}

Robust standard errors in parentheses $* * * p<0.01, * * p<0.05, * p<0.1$

Training $B$ means that iddir leadership received training $B$ 